Article

\title{
Specific Detection of Yersinia pestis Based on Receptor Binding Proteins of Phages
}

\author{
Friederike Born ${ }^{\dagger}$, Peter Braun ${ }^{\dagger}$, Holger C. Scholz and Gregor Grass * \\ Deptartment of Bacteriology and Toxinology, Bundeswehr Institute of Microbiology (IMB), 80937 Munich, \\ Germany; friederikeleonieborn@bundeswehr.org (F.B.); peter3braun@bundeswehr.org (P.B.); \\ holger1scholz@bundeswehr.org (H.C.S.) \\ * Correspondence: gregorgrass@bundeswehr.org; Tel.: +49-99-2692-3981 \\ + Both authors contributed equally to this work.
}

Received: 3 July 2020; Accepted: 24 July 2020; Published: 27 July 2020

\begin{abstract}
The highly pathogenic bacterium Yersinia pestis is the causative agent of plague, a notorious infectious zoonotic disease. When transmitted from person to person as pneumonic plague via droplets, Y. pestis is highly contagious and in most cases is fatal if left untreated. Thus, when plague is suspected, rapid diagnosis is crucial, as a serious course of the infection is only averted by early antibiotic therapy. The bacterium is easy to cultivate, accessible and has a high potential for nefarious use such as bioterrorism. Highly specific, rapid and easy-to-use confirmatory diagnostic methods are required to reliably identify the pathogen independently from PCR-based methods or F1 antigen-based immunological detection. Yersinia pestis specific phages such as L-413C and $\Phi$ A1122 are already used for detection of $Y$. pestis in bacterial plaque or biosensor assays. Here, we made use of the host specificities conferred by phage receptor binding (or tail fiber/spike) proteins (RBP) for developing a specific, fast and simple fluorescence-microscopy-based detection method for $Y$. pestis. Genes of putative RBP of phages L-413C $(g p H)$ and $\Phi$ A1122 ( $g p 17)$ were fused with those of fluorescent proteins and recombinant receptor-reporter fusion proteins were produced heterologously in Escherichia coli. When first tested on attenuated Y. pestis strain EV76, RBP-reporters bound to the bacterial cell surface. This assay could be completed within a few minutes using live or formaldehyde-inactivated cells. Specificity tests using cultures of closely related Yersinia species and several inactivated fully virulent Y. pestis strains exhibited high specificities of the RBP-reporters against $Y$. pestis. The L-413C RBP proved to be especially specific, as it only detected $Y$. pestis at all temperatures tested, whereas the RBP of $\Phi$ A1122 also bound to Y. pseudotuberculosis strains at $37^{\circ} \mathrm{C}$ (but not at 28,20 or $6{ }^{\circ} \mathrm{C}$ ). Finally, the $Y$. pestis-specific capsule, produced when grown at $37^{\circ} \mathrm{C}$, significantly reduced binding of phage ФA1122 RBP, whereas the capsule only slightly diminished binding of L-413C RBP.
\end{abstract}

Keywords: Yersinia pestis; plague; microscopic assay; pathogen detection; receptor binding protein; phage; tail fiber; tailspike; capsule; fluorescent reporter

\section{Introduction}

Plague is a notorious, highly contagious bacterial vector-borne disease typically transmitted between small mammals (rodents) and their fleas. The bacterium Yersinia pestis, the causative zoonotic agent of plague, is also highly pathogenic for humans. Broadly geographically distributed epidemics of the plaque bacterium had major social impact and economic consequences in the preantibiotics era. Y. pestis has caused three historically well-documented severe plague pandemics in the mid-6th, the mid-14th and the early 20th century [1].

The high pathogenicity of $Y$. pestis is largely due to its unique ability to successfully counter the defense mechanisms of both mammals and insects and to adapt to temperature fluctuations between 0 
and $37^{\circ} \mathrm{C}$ during its natural life cycle [2]. This includes the adjustment from a cold-blooded flea vector $\left(20-28^{\circ} \mathrm{C}\right)$ to a warm-blooded mammalian host $\left(37^{\circ} \mathrm{C}\right)$ and infected animals during hibernation $\left(6{ }^{\circ} \mathrm{C}\right)$. This adaptation to different growth temperatures has been associated with changes in the surface structure of Y. pestis [3].

During infection of mammals, $Y$. pestis secretes a surface antigen called fraction 1 (F1) protein forming a gel-like capsule [4]. This capsule is an important protective antigen for $Y$. pestis [5]. Besides being strongly antigenic, the capsule of $Y$. pestis functions as a virulence-associated surface structure that has antiphagocytic activity reducing uptake by macrophages and epithelial cells. Y. pestis is the only Yersinia species that at temperatures $>30^{\circ} \mathrm{C}$ produces this capsule composed of Caf1 subunits encoded by the caf1 gene located on plasmid pFra $[5,6]$.

The genus Yersinia contains two well-known mammalian enteropathogens, both of which cause yersiniosis, Y. enterocolitica and Y. pseudotuberculosis, the latter being closely related to Y. pestis. With the availability of genome sequences, a variety of Yersinia isolates originally typed as Y. pseudotuberculosis have now been reclassified into other species. These bacteria now belong to a group called "Y. pseudotuberculosis complex" including Y. pestis, Y. pseudotuberculosis, Y. similis and Y. wautersii [7].

After suspected infection with $Y$. pestis, rapid diagnosis is required, since a fatal course of the disease can only be averted by prompt antibiotic therapy. Antigen diagnostic methods (e.g., Enzyme-linked Immunosorbent Assay, ELISA), in which antigen detection is depending on antibodies, are very reliable [8-10], however, the assays are time consuming and have the disadvantage of delayed detection, since positive results can only be reliably established several days after the bacterium has multiplied considerably inside the host. Therefore, these methods are typically used for confirmation only. Currently, the detection of $Y$. pestis is generally founded on a combination of several methods. Culture-based identification by subsequent microscopy provides rather tentative results; more precise results are obtained by the detection of antigens (e.g., the F1 capsule antigen) and by molecular genetic identification using polymerase chain reaction (PCR) e.g., on virulence gene markers pla and caf constituting a diagnostic standard for the plague pathogen [11,12]. PCR can also be combined with other means of detection such as bacteriophage (phage) plaque diagnostics but such methods take considerable time [13]. The time issue can be ameliorated when recombinant, light emitting phages are constructed for assays measured in hours instead of days [14]. A clear advantage of additional rapid and specific microscopy-based detection methods would be that these could independently confirm PCR results: a combination necessary for a complete diagnostic algorithm.

We hypothesized that receptor binding proteins (RBP) of host-specific bacteriophages of Y. pestis [15, 16] could close this diagnostic gap. Phages are the most numerous and versatile organisms on earth [17]. For $Y$. pestis phages, as for other phages, receptor recognition is usually a highly specific process and is part of the natural mechanism of host adsorption $[18,19]$. The susceptibility of a bacterium to phage infection primarily depends on whether the phage is able to find its specific attachment sites, i.e., its receptors on the host cell surface. Phages can be divided into temperate or lytic phages based on their life cycles. In contrast to temperate phage, infection by lytic phage always leads to lysis of the bacterial cell and to the release of new phage progeny. However, the first step of an infection cycle is always the adsorption of the phage on the bacterial surface. In tailed phages, this binding is usually mediated by phage structural proteins, the RBP [20].

The order Caudovirales (tailed phage) consists of the three families: Myoviridae, Siphoviridae and Podoviridae and comprises about $96 \%$ of all known phages [20]. The phages specific to the genus Yersinia, the Yersinia phages, also cover these families. Among these, Y. pestis phages differ in their antigenic properties, morphology of their virions, host virulence, genome structure and degree of specificity for the pathogen. Two well-characterized diagnostic phages of $Y$. pestis (relevant for this work) are L-413C [15] and $\Phi$ A1122 [16]. Phage $\Phi A 1122$ belongs to the Podoviridae family and has a short noncontractile tail. Sequence analyses showed strong similarity of the $\Phi A 1122$ phage to the Escherichia coli phages T3 and T7 [16]. Phage L-413 was isolated from the Y. pestis strain 413 and after several passages in the $Y$. pestis host strain, the lytic mutant L-413C phage was obtained, which only 
lyses Y. pestis but not Y. pseudotuberculosis or the vast majority of E. coli strains [15,21]. Phage L-413C is similar to the P1, P2 and P4 phages [15] belonging to the Myoviridae family featuring a relatively long contractile tail. Previously, it has been shown that the plague diagnostic phages L-413C and $\Phi A 1122$ are very specific to Y. pestis and allow the differentiation of Y. pestis from Y. pseudotuberculosis strains $[15,16]$.

For asserting host specificity and to initiate the infection process, diverse phage tail structures constitute key factors of tailed phages. RBP at the distal end of these tails interact with bacterial cell surface structures. Tail fiber, tailspike or tail tip (or tail nozzle) proteins can act as RBP and specifically recognize host receptors such as cell wall lipopolysaccharides (LPS), teichoic acids or proteins (e.g., porins) [20]. Typically, RBP are homotrimeric complexes and often consist of two critical domains. The amino terminus of the RBP typically connects the RBP to the rest of the phage, whereas the carboxy terminus, which is oriented away from the phage, forms the binding domain for the host receptor [22-24]).

Receptor recognition of phages of the T7 group is mediated by the tail fiber protein Gp17. Due to the similarity of the $\Phi A 1122$ phage to other phages of the T7 group, Garcia et al. (2003) and Kiljunen et al. (2011) postulated that Gp17 of $\Phi$ A1122 was responsible for receptor recognition $[16,18]$. The RBP of the T7 and T3 phages are 98.9 and 81\% identical to Gp17 of $\Phi$ A1122, respectively. It was therefore assumed that $\Phi A 1122$ can as well bind to LPS. Protein GpH of the L-413C phage is the likely tail fiber protein of this phage $[15,19]$. For $\mathrm{GpH}$ a possible function as a RBP was inferred from similarity to its homolog in P2-like phages [15]. Since the host range of P2-like phages is determined by the tail fibers, the authors postulated host specificity is exerted by $\mathrm{GpH}$, the closely related putative tail fiber protein of the phage L-413C.

From this knowledge base we aimed to experimentally test the hypotheses put forth earlier through in silico considerations $[15,16]$ that the putative gene products of $g p 17$ (phage $\Phi$ A1122) and $g p H$ (phage $\mathrm{L}-413 \mathrm{C}$ ) constitute the RBP of these $Y$. pestis phages. For this, the putative phage RBP of phages L-413C and $\Phi A 1122$ were produced in heterologous host $E$. coli coupled to fluorescent reporter proteins and the recombinant proteins purified. From there we developed a specific fluorescence microscopy detection assay for $Y$. pestis using these RBP fusion reporter proteins by testing specificities to cells of $Y$. pestis and other Yersinia spp. under different growth temperatures and capsule inducing conditions.

\section{Results}

\subsection{Fluorescent Fusion Proteins of the Putative RBP of Phages L-413C or $\Phi$ A1122 Can be Heterologously} Produced in E. coli

The putative RBP genes of the Yersinia phages L-413C $(g p H)$ and $\Phi$ A1122 ( $g p 17)$ were cloned as fusions with genes of fluorescence reporter proteins (eGFP and mCherry) and a Twin-Strep-tag (TST) epitope (located at the N-terminus of the resultant fusion protein). Recombinant expression plasmids tested positive by colony PCR and Sanger DNA-sequencing were transferred into production strain E. coli ArcticExpress and protein biosynthesis was initiated. Cells were lysed and cleared lysates used for affinity chromatography. Expected sizes of fusion proteins were confirmed by Western blot analysis. Supplementary Figure S1 shows representative stained bands of eGFP-RBP (phage L-413C $\mathrm{GpH} ; 130 \mathrm{kDa}$ ) and eGFP-RBP (phage $\Phi$ A1122 Gp17; $93.5 \mathrm{kDa}$ ) fusion proteins.

\subsection{Binding of Fluorescent RBP Fusion Proteins of Phages L-413C and $\Phi A 1122$ to Y. pestis Cells}

Next, the putative RBPs were examined for binding to Y. pestis cells. For this, a culture of $Y$. pestis strain EV76 was grown to exponential (logarithmic) growth phase at $28^{\circ} \mathrm{C}$ and samples processed for fluorescence microscopy. For analysis of binding of phage L-413C RBP, a red fluorescence reporter (mCherry) and for phage $\Phi$ A1122 RBP a green fusion reporter (eGFP) was used. The results depicted in Figure 1 strongly supported the hypothesis predicting that GpH is the RBP of phage L-413C and Gp17 that of phage $\Phi A 1122$. Each of the two RBP fusion reporters extensively attached to the surfaces 
of $Y$. pestis cells. This test was fast; the steps from harvesting cultures to imaging and taking pictures can be accomplished within approximately $20 \mathrm{~min}$.
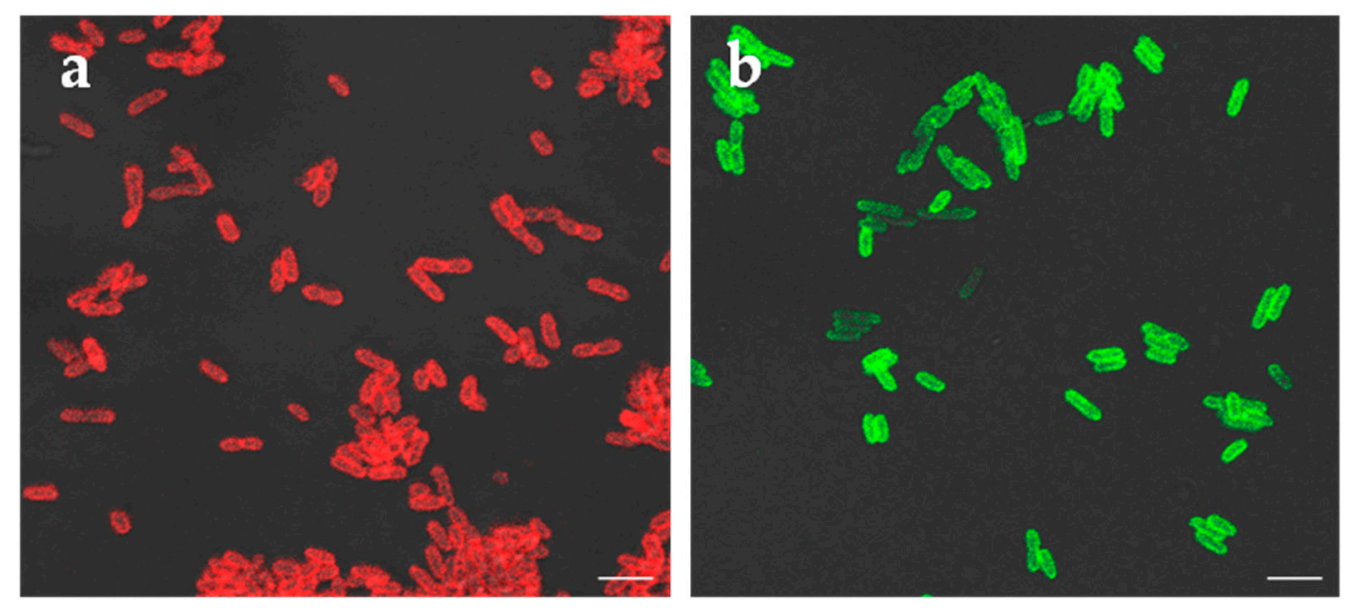

Figure 1. Binding of fluorescent receptor binding proteins (RBP) fusion reporters of Yersinia phages L-413C and $\Phi A 1122$ to Y. pestis cells. (a) mCherry fused to RBP of phage L-413C (red signals) or (b) eGFP fused to RBP of phage $\Phi$ A1122 (green signals) were added to cells of logarithmically growing Y. pestis cultures, washed with buffer to remove unbound reporter proteins, transferred to microscopy slides and subjected to fluorescence microscopy. Shown are representative fluorescence signals recorded at $630 \times$ magnification (scale bar: $5 \mu \mathrm{m}$ ).

\subsection{Time Course of Fluorescent RBP Fusion Protein Binding to Y. pestis Cells}

For the next line of experiments, RBP binding at several different culture temperature regimens was tested. This was done to address the temperature-dependent structural changes of the LPS composition of $Y$. pestis. Different pairs of adjacent, inner nuclear residues of the LPS, more precisely the terminal residue of the outer core ( $\mathrm{N}$-acetylglucosamine), were previously identified as surface receptors for phage L-413C and 3-deoxy-D-manno-octulosonic acid (Kdo) and its isosteric 3-hydroxy derivative d-glycero- $\alpha$-d-talo-oct-2-ulosonic acid (Ko) for phage $\Phi$ A1122 $[18,19]$. In order to mimic different hosts of $Y$. pestis, the growth temperature of $Y$. pestis cultures were varied and binding of the RBP-reporters analyzed. Individually, the different growth temperatures were to represent the typical body temperature of an active mammal $\left(37^{\circ} \mathrm{C}\right)$, the optimum growth temperature of $Y$. pestis $\left(28^{\circ} \mathrm{C}\right)$, the (ambient) temperature in flea host $\left(20^{\circ} \mathrm{C}\right)$ and the body temperatures of a mammal in hibernation $\left(6^{\circ} \mathrm{C}\right)$. For each growth temperature, culture samples were taken hourly for a duration of $12 \mathrm{~h}$ and after $24 \mathrm{~h}$ in order to record temperature-dependent time-courses of RBP-reporter binding.

Figure 2 shows binding of the mCherry-RBP (phage L-413C) or the eGFP-RBP (phage $\Phi$ A1122) fusion proteins at representative time points during growth at temperatures listed above. Already at early logarithmic phases after $2 \mathrm{~h}, \mathrm{RBP}$ binding was observed across all temperatures tested. With the exception of the $6^{\circ} \mathrm{C}$ culture, fluorescence (red) mediated by binding of phage L413C-RBP to bacterial cells appeared to be more extensive than that of phage $\Phi A 1122-R B P$. Fluorescence increased over the next hours and strong signals were recorded for phage L413C-RBP binding after $4 \mathrm{~h}\left(6^{\circ} \mathrm{C}\right), 2-3 \mathrm{~h}$ $\left(20^{\circ} \mathrm{C}\right), 4-10 \mathrm{~h}\left(28^{\circ} \mathrm{C}\right)$ and $2-12 \mathrm{~h}\left(37^{\circ} \mathrm{C}\right)$ as well as of phage $\Phi$ A1122-RBP binding after $2-6 \mathrm{~h}\left(6^{\circ} \mathrm{C}\right)$, $3-4 \mathrm{~h}\left(20^{\circ} \mathrm{C}\right), 2-10 \mathrm{~h}\left(28^{\circ} \mathrm{C}\right)$ and $2-6 \mathrm{~h}\left(37^{\circ} \mathrm{C}\right)$. Overnight $(24 \mathrm{~h})$ cultures only fluoresced dimly (both RBP at $37^{\circ} \mathrm{C}$ ) or patchy (phage L413C-RBP at $28^{\circ} \mathrm{C}$ ) or not at all (both RBP-reporters at 6 and $20^{\circ} \mathrm{C}$ as well as phage $\Phi$ A1122-RBP at $28^{\circ} \mathrm{C}$ ).

Binding of the RBP-reporter proteins was also assessed in a more semiquantitative manner (by visual comparison) as the increase (or strength) of the fluorescence signal over time, which indicated increased (extensive) binding of the fusion proteins, or as diminished fluorescence signal, which indicated diminished binding of the fusion proteins (Figure 3). For this, analysis of RBP-reporter 
binding was coupled to culture growth experiments from lag to logarithmic and stationary growth phases. In Figure 3 grey lines indicate periods of cell growth in which the RBP-reporters did not bind at all. During periods of extensive RBP-reporter binding, cells fluoresced strongly (indicated as dark-colored lines), while for transition phases, diminished fluorescence signals are represented by light colors.

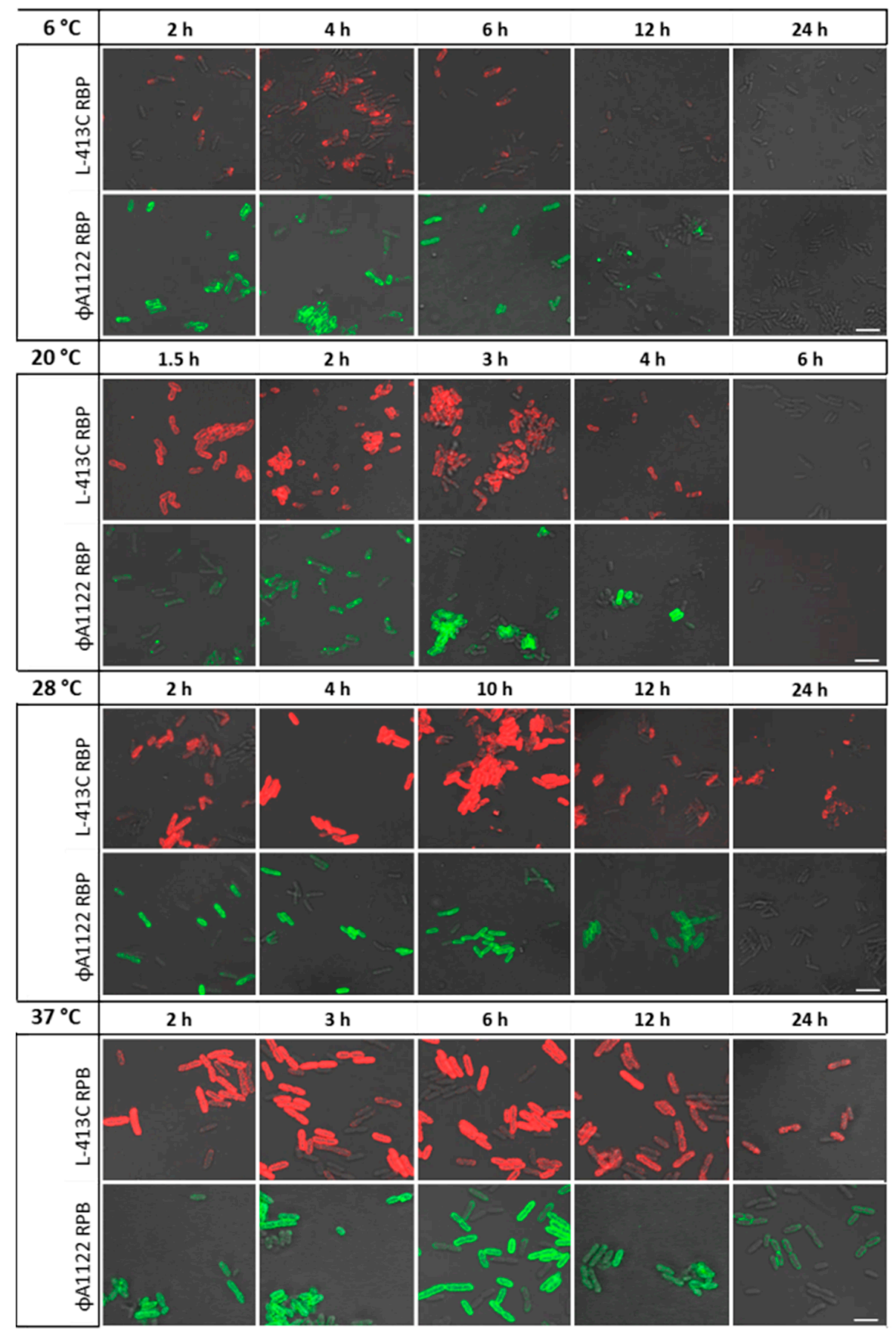

Figure 2. Time course of binding of Yersinia phage RBP fusion reporters to Y. pestis cells. Cultures of Y. pestis EV76 were grown from lag to exponential (logarithmic) and stationary phase and samples withdrawn at representative time points for RBP binding assays. Individual micrographs are shown for mCherry-RBP fusion protein (phage L-413C; red signal) or eGFP-RBP fusion protein (phage ФA1122; green signal) binding to $Y$. pestis cells at $6,20,28$ and $37^{\circ} \mathrm{C}$ (recorded in merged light and fluorescence channels; scale bar: $5 \mu \mathrm{m}$ ). 

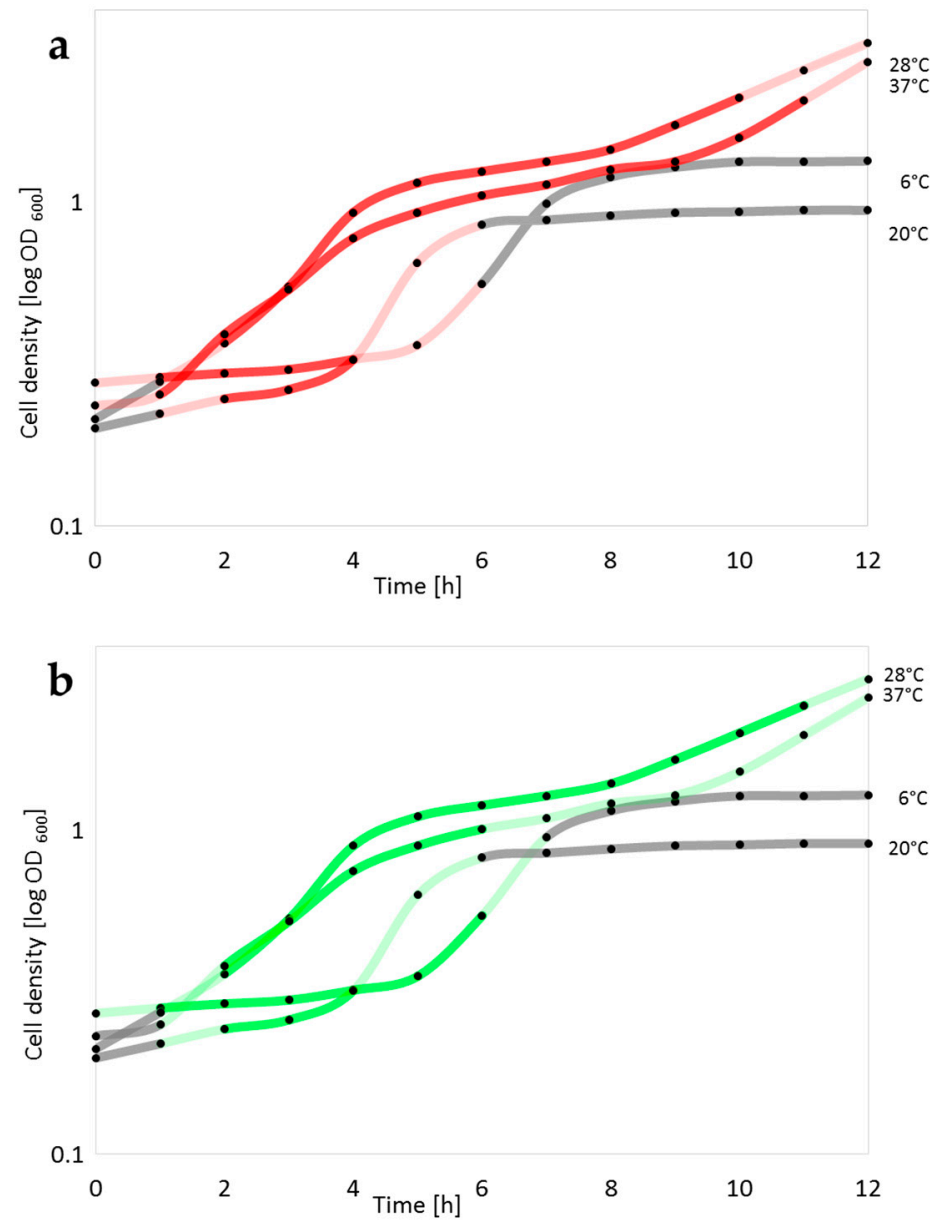

Figure 3. Semiquantitative representation of binding of Yersinia phage RBP fusion reporters to Y. pestis cells. Micrographs taken from culture samples withdrawn at different time points (growth phases) from growth experiments at $6,20,28$ or $37^{\circ} \mathrm{C}$ (see Figure 2 for representative examples) were visually analyzed for RBP-reporter binding to Y. pestis EV76 cells. (a) mCherry-RBP (phage L-413C; red) or (b) eGFP-RBP (phage $\Phi$ A1122; green) fusion proteins. Binding of the reporters was assessed by an increase or decrease (light colors) of fluorescence signals (and phases with constant strong signals; dark colors) and plotted onto data (black dots) from actual growth curve experiments (measurements of optical culture densities at $600 \mathrm{~nm}$ ). Periods with lack of visual fluorescence signals indicating no RBP binding, were scored as grey lines.

For binding of the mCherry-RBP fusion protein (phage L-413C) to Y. pestis EV76 at $6{ }^{\circ} \mathrm{C}$, after weak binding right on from the beginning, further increase of the fluorescence signal was detected from $1 \mathrm{~h}$ onwards, which indicated extensive RBP binding during this time period (Figure 3a). A decrease in fluorescence signal intensity, indicating diminished RBP-reporter binding, was detected after $4 \mathrm{~h}$ but the signal could be detected until $6 \mathrm{~h}$. Thus, the optimum time period for binding of this RBP at $6^{\circ} \mathrm{C}$ was late lag and early exponential phase of the cells in culture. At $20^{\circ} \mathrm{C}$ the signal strength increased after $1 \mathrm{~h}$. The range with constant strong signal strength was 2 to $4 \mathrm{~h}$, followed by a decrease of the fluorescence signal over the next $2 \mathrm{~h}$. An extended binding period was observed for RBP binding at $28^{\circ} \mathrm{C}$. The maximum fluorescence period ranged from 2 to $10 \mathrm{~h}$. The longest maximum intensity binding period of phage L-413C-RBP was recorded from cells cultivated at $37^{\circ} \mathrm{C}$. This period lasted from 1 to $11 \mathrm{~h}$ and then the signal declined.

Similar results were obtained for binding of the eGFP-RBP (phage $\Phi$ A1122) fusion protein (Figure 3B). At $6{ }^{\circ} \mathrm{C}$, strong fluorescence signals were observed from 1 to $6 \mathrm{~h}$, at $20^{\circ} \mathrm{C}$ a short maximum binding period was reached between 2 and $4 \mathrm{~h}$ after culture inoculation. At $28^{\circ} \mathrm{C}$ the longest maximum 
binding period for this RBP was recorded, lasting from 2 to $11 \mathrm{~h}$. Finally, at $37^{\circ} \mathrm{C}$ this period diminished to 2 to $6 \mathrm{~h}$ fading out with completion of exponential phase growth.

Notably, binding of the mCherry-RBP (phage L-413C) fusion protein to cells produced a significantly weaker overall fluorescence signal at $6^{\circ} \mathrm{C}$ than at $20-37^{\circ} \mathrm{C}$. This was also observed for the eGFP-RBP (phage $\Phi$ A1122) fusion protein: weaker fluorescence signal at $6{ }^{\circ} \mathrm{C}$, but the strongest signals for this RBP fusion were observed at $28^{\circ} \mathrm{C}$ and $37^{\circ} \mathrm{C}$ (compare Figure 2). We also noted that Y. pestis EV76 cells became significantly larger at an incubation temperature of $37^{\circ} \mathrm{C}$ than at all other temperatures (including the organism's preferred growth temperature of $28^{\circ} \mathrm{C}$; compare Figure 2).

Taken together, the proposed function of $\mathrm{GpH}$ (of phage L-413C) and Gp17 (of phage $\Phi$ A1122) by employing fluorescent fusion protein technology could be experimentally supported. Thus, GpH and Gp17 are most likely the RBP of their respective Yersinia phages and these RBPs bind to their host cells at several relevant growth temperatures.

2.4. The Y. pestis Capsule does not Seem to Impair Phage L-413C RBP Binding to Cells Whereas Binding RBP of Phage $\Phi A 1122$ is Diminished

The capsule-like fraction 1 (F1) antigen expressed by $Y$. pestis is a well-characterized, specific marker for the identification of the plague pathogen. Capsule biosynthesis by $Y$. pestis occurs at cultivation conditions above $30{ }^{\circ} \mathrm{C}$. $[5,6]$. This physical proteinous barrier can be expected to have a negative influence on the binding of RBPs. To test this, detection of $Y$. pestis by binding of RBP-reporters was combined with antibody-mediated detection of the F1 antigen. Figure 4 shows binding of the fusion reporters mCherry-RBP (phage L-413C) and eGFP-RBP (phage ФA1122), respectively, to growing $Y$. pestis cultures during a time period from 0 and $24 \mathrm{~h}$ after inoculation. Capsule formation was visualized by monoclonal antibodies against the F1 capsule antigen coupled with a secondary fluorescent detection antibody. The fluorescence signal of the antibody increased over time, indicating capsule formation (Figure 4). Concomitantly, the fluorescence signal of the $\Phi$ A1122-RBP-reporter decreased, suggesting diminished RBP binding in the presence of capsule. Of note, only a fraction of cells synthesized capsules and this fraction increased over time. Thus, RBP-reporter binding to non-encapsulated cells was still possible.

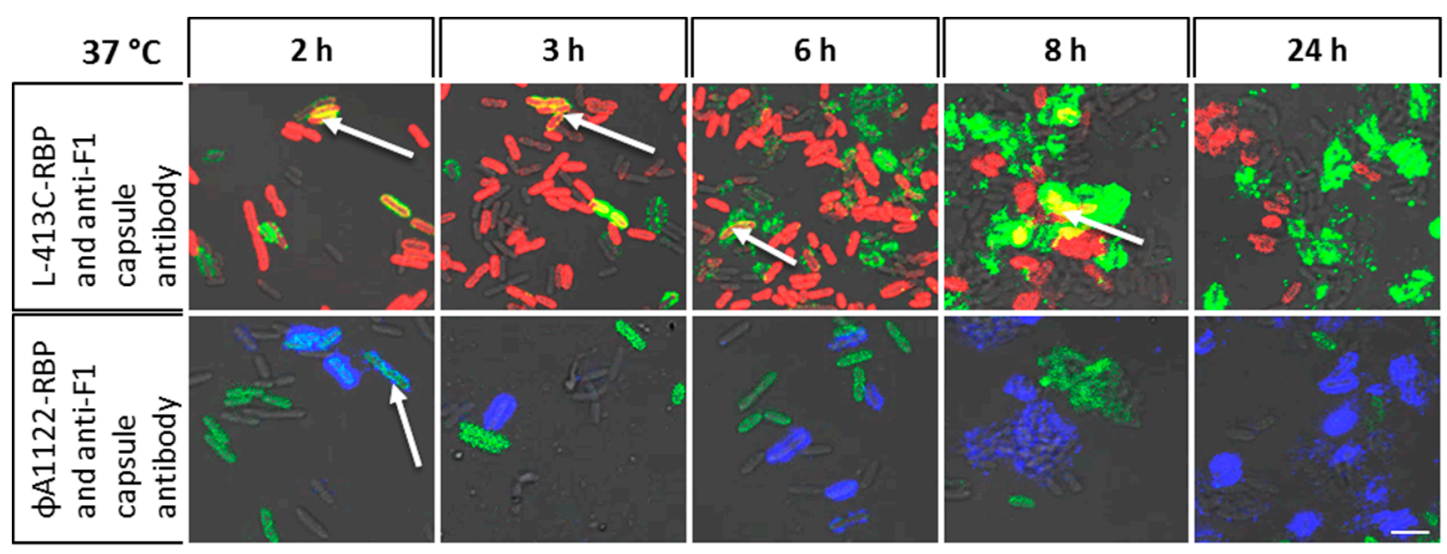

Figure 4. Binding of RBP fusion reporters to growing cultures of $Y$. pestis EV76 cells at $37^{\circ} \mathrm{C}$. In this representation, capsule formation is detected by means of monoclonal anti-F1 capsule antigen antibody in combination with secondary antibody labelled with Alexa Fluor 488 (green fluorescence, upper panels only) for co-detection with L-413C-RBP or Alexa Fluor 647 (false color blue fluorescence, lower panels only) for co-detection with $\Phi$ A1122-RPB, respectively. RBP binding to Y. pestis EV76 cells at indicated time points at $37^{\circ} \mathrm{C}$ is shown as individual representative micrographs for phage L-413C mCherry-RBP-reporter (red signals) or phage $\Phi$ A1122 eGFP-RBP-reporter (green signals) as merges with fluorescent antibody signals (and recorded in merged light and fluorescence channels). Arrows indicate doubly labelled cells with RBP-reporters and antibodies (scale bar: $5 \mu \mathrm{m}$ ). 
Binding of fusion protein mCherry-RBP (phage L-413C) yielded different results. Despite increasing fluorescence signals caused by anticapsule antibody binding to cell surfaces, no marked decrease in the fluorescence signal of the RBP-reporter was noted over the covered time period (Figure 4). Even when the fluorescence signal of the antibody was strong, cells showing superimposition of the fluorescence signals of both the antibody and the RBP-reporter were visible (yellow cells labelled by a blue arrow in Figure 4; upper $8 \mathrm{~h}$ micrograph). This indicated largely unhindered RBP binding to cells despite capsule formation. Thus, capsule formation had only a negligible influence on the RPB protein of phage L-413C. Similar to the results for phage $\Phi$ A1122 RBP, not all cells were capsulated, so all cells were labelled by the phage L-413C-RBP-reporter (compare also RBP binding in Figure $2,37^{\circ} \mathrm{C}$ micrographs of cells without capsule staining). Cells grown at $28^{\circ} \mathrm{C}$ did not produce any capsule and thus were not labeled by anticapsule F1-antigen antibodies (Figure S2). Capsule formation detected by anti-F1 antigen antibody staining of cells grown at $37^{\circ} \mathrm{C}$ (Figure 4) was confirmed by using the Plague Bio Threat Alert rapid test performed with the same Y. pestis EV76 cultures used for microscopy. However, in contrast to the RBP-based assay, the lateral flow assay solely recognizes the presence of capsulated cells but not their relative abundance.

\subsection{Binding of Phage RBP-Reporters is Specific for Y. pestis Cells}

In the next series of experiments, we examined RBP binding to cells of species closely related to Y. pestis. These comprised risk group 2 pathogens of the genus Yersinia such as $Y$. pseudotuberculosis, Y. enterocolitica subsp. enterocolitica and Y. enterocolitica subsp. palearctica, Y. wautersii and Y. similis. Binding tests were conducted with bacterial cultures grown at 28 and $37^{\circ} \mathrm{C}$, respectively. Figure 5 shows specificity tests for mCherry-RBP (phage L-413C, red signals) and eGFP-RBP (phage $\Phi A 1122$, green signals) as representative micrographs after $4 \mathrm{~h}$ of bacterial growth, a time period optimum for RBP binding (compare Figure 3). RBP binding at additional cultivation time points was also analyzed with similar results. At $28^{\circ} \mathrm{C}$, neither RBP-reporter bound to cells of any other Yersinia spp. except Y. pestis (Figure 5a).

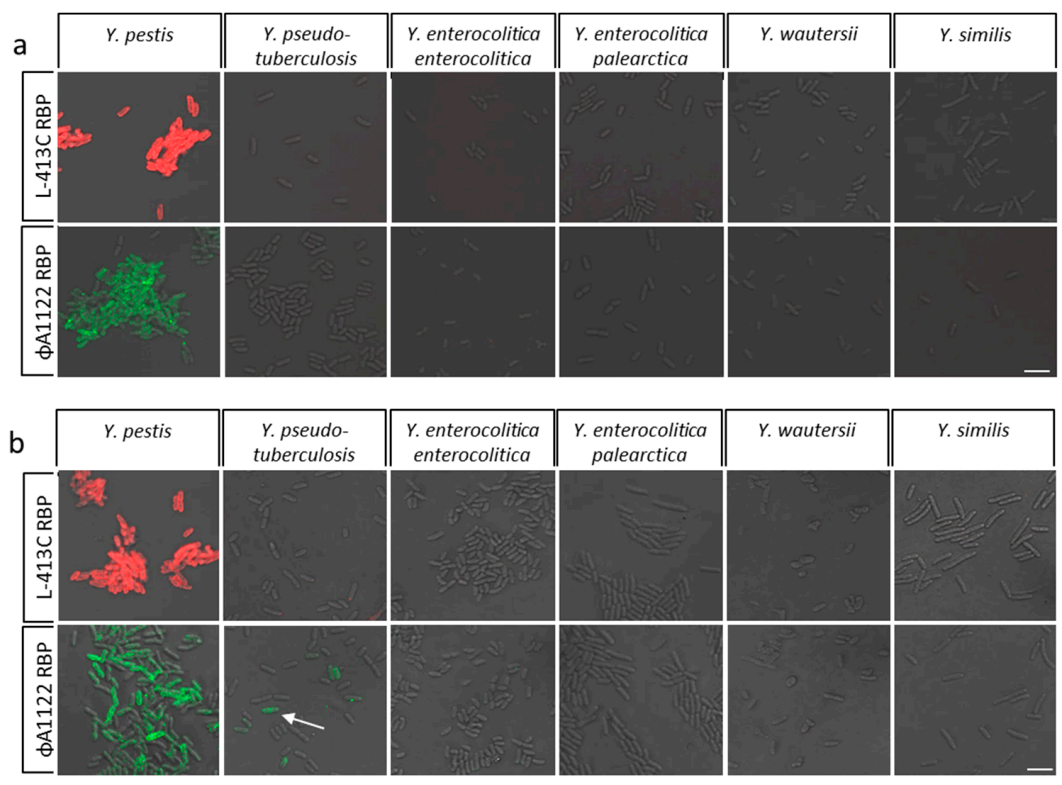

Figure 5. Specificity tests of the RBP-reporters binding to cells of Yersinia spp. closely related to Y. pestis. Cultures of several Yersinia spp. (as indicated) and of Y. pestis EV76 as positive control were grown at $28^{\circ} \mathrm{C}(\mathbf{a})$, or $37^{\circ} \mathrm{C}(\mathbf{b})$. After $4 \mathrm{~h}$ of growth, samples were withdrawn, incubated with mCherry-RBP-reporter (from phage L-413C; red signals) or eGFP-RBP-reporter (from phage ФA1122; green signals) and subjected to fluorescence microscopy (recorded in merged light and fluorescence channels). The arrow indicates an individual cell labelled by the RBP-reporter (scale bar: $5 \mu \mathrm{m}$ ). 
When cultures were grown at $37^{\circ} \mathrm{C}$, Y. enterocolitica, Y. wautersii and Y. similis yielded no fluorescence signals (Figure $5 b$ ) indicating the absence of either RBP-reporter binding to these cells. In contrast, cells of $Y$. pseudotuberculosis were partially labelled by RBP of phage $\Phi$ A1122 but not by RBP of phage L-413C at this growth temperature. It can therefore be proposed that binding of either RBP to $Y$. pestis was specific to cells grown at $28^{\circ} \mathrm{C}$. However, only the RBP of phage L-413C was able to differentiate $Y$. pestis from its genetically closest relative $Y$. pseudotuberculosis at $37^{\circ} \mathrm{C}$.

To further investigate RBP binding to $Y$. pseudotuberculosis cells at $37^{\circ} \mathrm{C}$, additional isolates were tested as shown in Figure 6. The red RBP-reporter of phage L-413C yielded no fluorescence signals and thus did not bind to these cells. In contrast, binding of the green RBP-reporter of phage $\Phi A 1122$ to $Y$. pseudotuberculosis cells was confirmed. As a consequence, it seems not advisable to use the phage $\Phi$ A1122 RBP for identification of $Y$. pestis grown at $37^{\circ} \mathrm{C}$, e.g., when provided as a clinical sample from a patient. Instead, application of the RBP-reporter of phage L-413C is probably a better, more specific choice.

\subsection{Specificity Testing of Phage RBP-Reporters on Inactivated Y. pestis Cells of Risk Group 3}

Experimentation with live, highly pathogenic $Y$. pestis cells of risk group (RG) 3 is often not practical or readily possible, e.g., in field settings. To address this challenge, four different inactivation methods for $Y$. pestis were compared for their compatibility with subsequent RBP binding assays. For all methods, complete sterility of the RG-2 test organism Y. pestis EV76 was confirmed by cultivating the inactivated cells. We found that both inactivation with peracetic acid or with heat resulted in strong morphological changes to the dead cells and therefore the use of these methods as an upstream step prior to RBP-reporter labelling and microscopy was abandoned. Inactivation with ethanol led to the formation of cell clumps. As a consequence, subsequent RBP binding tests using cells inactivated with ethanol showed rather punctiform, non-uniform fluorescence signals that did not cover entire surfaces (Figure 7 , center micrographs). Inactivation with $4 \%$ paraformaldehyde (PFA), however, proved to be the most suitable method, both in terms of conserving cell morphology, of retaining strong fluorescence signals and of uniform RBP binding to the entire cell surface (Figure 7, right micrographs). Therefore, inactivation with $4 \%$ PFA was used for subsequent specificity assays on RG-3 Y. pestis strains next.

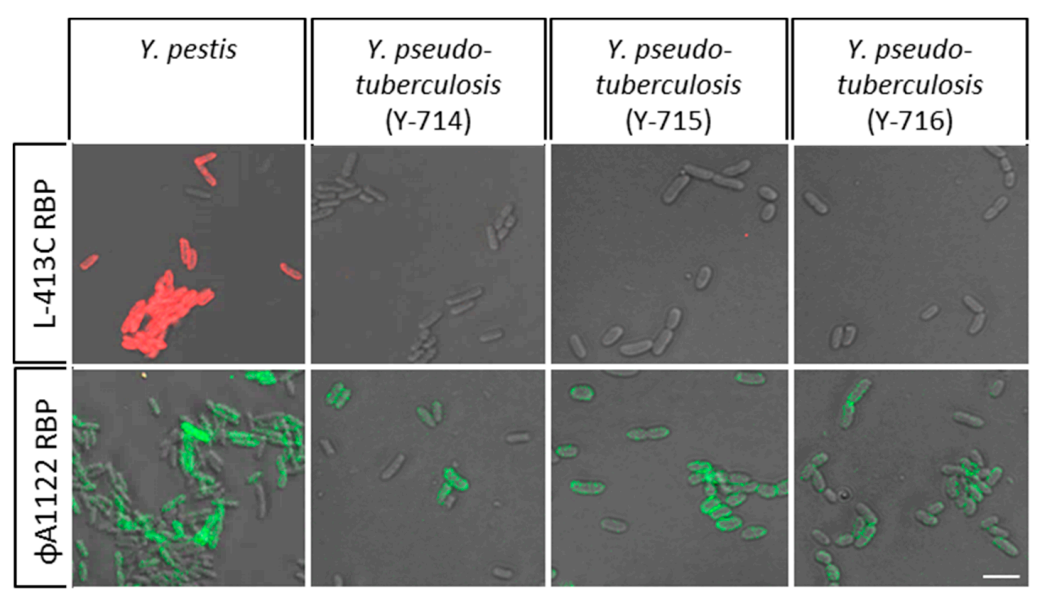

Figure 6. Binding of RBP-reporters to cells of additional Y.pseudotuberculosis strains at $37^{\circ} \mathrm{C}$. Cultures and samples of three Y. pseudotuberculosis O:1a strains were treated as described in Figure 5), mCherry-RBP (from phage L-413C; red signals) or eGFP-RBP fusion proteins (from phage $\Phi$ A1122; green signals) were added and samples subjected to fluorescence microscopy (recorded in merged light and fluorescence channels; scale bar: $5 \mu \mathrm{m}$ ).

In order to avoid the cultivation of RG-3 Y. pestis strains in liquid medium in a BSL-3 environment, we tested using RG-2 Y. pestis EV76 whether cultivation on solid growth media is compatible with RBP binding. This test was carried out over a cultivation period of up to $24 \mathrm{~h}$. Between 6 to $8 \mathrm{~h}$, 
strong fluorescence signals could be detected indicating binding of the fusion proteins mCherry-RBP (phage L-413C) and eGFP-RBP (phage $\Phi$ A1122) to the bacterial surfaces. Next, a variety of six RG-3 Y. pestis strains of diverse phylogenetic subgroups were grown on solid BHI media for 6 to $7 \mathrm{~h}$ at $28{ }^{\circ} \mathrm{C}$ and then inactivated by PFA. After incubation with RBP-reporters, strong fluorescence signals were detected for cells of all six RG-3 Y. pestis strains using either reporter, mCherry-RBP (phage L-413C) or eGFP-RBP (phage $\Phi$ A1122) indicating efficient RBP binding to inactivated cells (Figure 8). This confirmed results obtained using attenuated RG 2 strain Y. pestis EV76 (compare Figure 7). Thus, cultivation on solid media and inactivation with 4\% PFA was suitable for assaying RG-3 Y. pestis strains. Moreover, microscopic re-examination of the inactivated cells two weeks after inactivation could still be successfully performed. There were no changes in the cell morphologies and efficacies of RBP-reporter binding to the PFA-inactivated cells when samples were stored at $4{ }^{\circ} \mathrm{C}$.

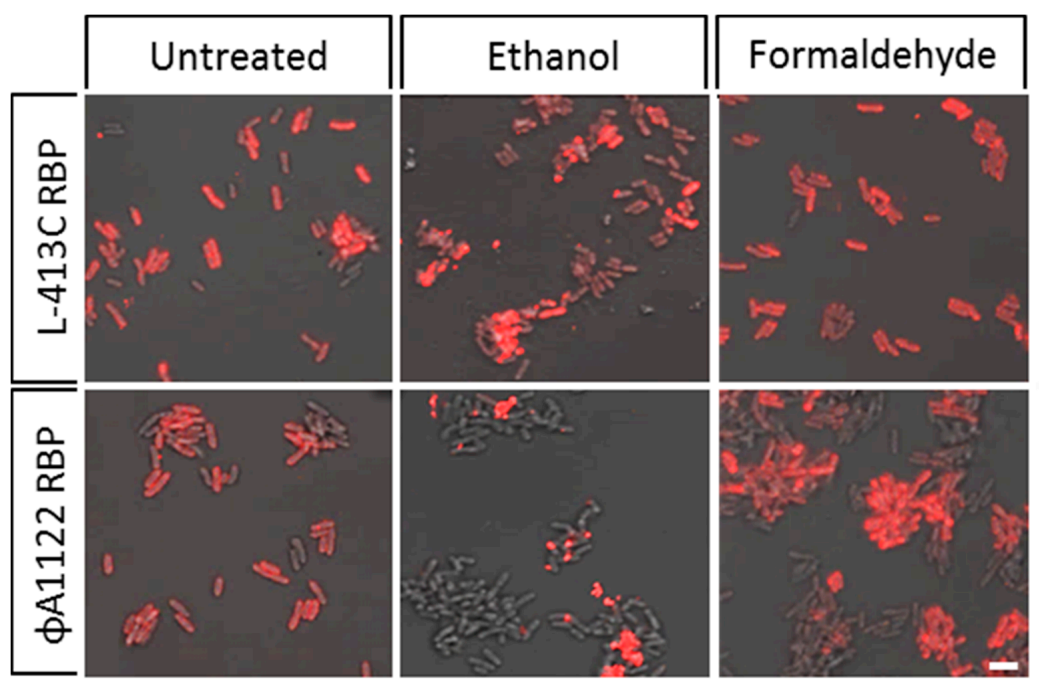

Figure 7. Binding of RBP-reporters to inactivated cells of $Y$. pestis. Cells of Y. pestis EV76 grown for $7 \mathrm{~h}$ at $28^{\circ} \mathrm{C}$ were inactivated as indicated, washed with PBS buffer, incubated with fusion proteins mCherry-RBP (phage L-413C; red signals, upper panels) or mCherry-RBP (phage ФA1122; red signals lower panels) and subjected to fluorescence microscopy (recorded in merged light and fluorescence channels). Untreated cells served as positive controls (scale bar: $5 \mu \mathrm{m}$ ).

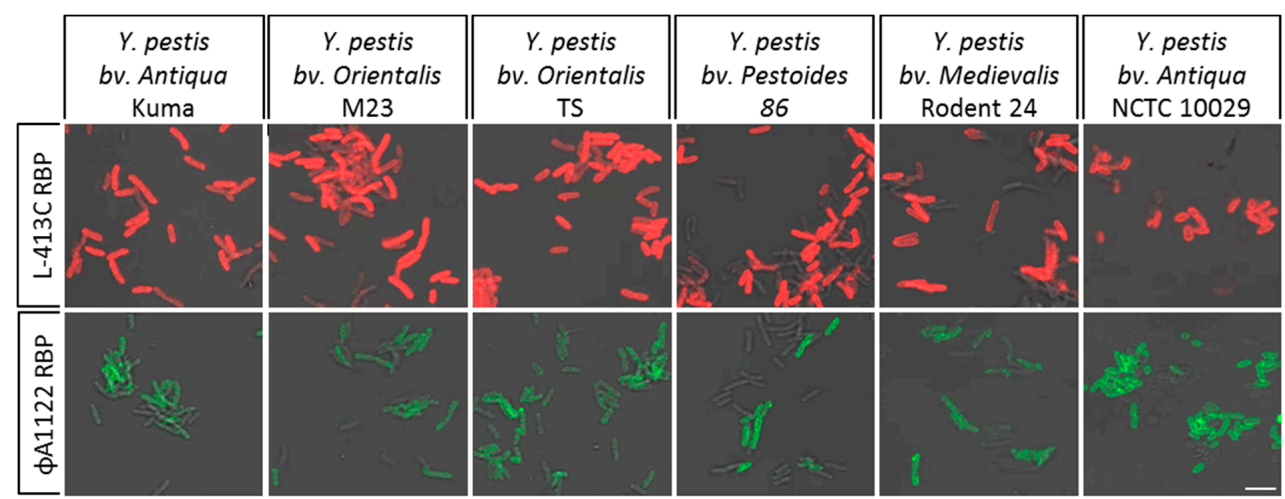

Figure 8. Binding of RBP-reporters to inactivated cells of RG-3 Y. pestis. Cells of Y. pestis grown for $7 \mathrm{~h}$ at $28^{\circ} \mathrm{C}$ on solid BHI media were inactivated with $4 \%$ PFA. Inactivated cells were incubated with fusion proteins mCherry-RBP (phage L-413C; red signals, upper panels) or eGFP-RBP (phage ФA1122; green signals lower panels) and subjected to fluorescence microscopy (recorded in merged light and fluorescence channels). Strains tested represent a phylogenetically diverse set of $Y$. pestis isolates as indicated (scale bar: $5 \mu \mathrm{m}$ ). 


\section{Discussion}

In Y. pestis, as in most Gram-negative bacteria which are surrounded by an outer membrane, the inner layer of the outer membrane contains lipoproteins whereas the outer layer features LPS moieties which constitute a heterologous population of amphiphilic macromolecules [2]. In addition, embedded in this unique membranous structure are outer membrane proteins (OMP) which play a critical role in translocation of solutes and proteins, in pathogenesis, as well as in signal transmission. Both OMP and LPS can act as specific phage receptors [18-20].

The specificity of phage-host interactions is typically defined by both phage RBP and the type and structure of host receptor(s). For this, receptor localization, as well as receptors abundance and density on the cell surface may modulate specificity [20]. Phylogenetically different phages infecting the same bacterial species often have different receptors [20]. This is also observed for the two Yersinia phages L-413C and $\Phi A 1122$. Each of these phages binds to different structures of the Y. pestis LPS core. While the L-413C phage uses the terminal residue ( $\mathrm{N}$-acetylglucosamine) of the LPS as surface receptor, the surface receptor of phage $\Phi A 1122$ is 3-deoxy-D-manno-octulosonic acid (Kdo) and its isosteric 3-hydroxy derivative d-glycero- $\alpha$-d-talo-oct-2-ulosonic acid (Ko). In addition to these critical receptor structures, two pairs of adjacent LPS sugar residues of the LPS core are also involved in phage adsorption [19].

The LPS core structures of Gram-negative bacteria contain several heptoses, as well as glucose and galactose, which are tethered to lipid A via Kdo. Only a limited diversity of LPS between species is observed [25]. The LPS of Y. pestis differs from that of other Yersinia spp. in that it is rough, i.e., the O-antigen polysaccharide chain consisting of oligosaccharide repeat units is missing $[2,18,25]$. The missing O-polysaccharide chain is due to a nonfunctional O-antigen gene cluster caused by several frame-shift mutations [26,27]. The LPS of $Y$. pestis therefore consists of a short carbohydrate chain bound to lipid A $[18,28])$. The inner nuclear region acts as a receptor for most bacteriophages specific for the LPS of Y. pestis but the lipid A and nuclear oligosaccharide structures of Y. pestis and Y. pseudotuberculosis LPS are largely identical [2]. The S-type LPS, which is typical for most bacteria forming smooth colonies and is also found in Y. pseudotuberculosis and Y. enterocolitica [26], additionally contains the O-antigen (oligosaccharide repeat units) [2]. In Y. enterocolitica and Y. pseudotuberculosis, $\mathrm{O}$-antigen expression is temperature regulated. Bacteria cultivated at room temperature produce large amounts of $\mathrm{O}$-antigen, whereas at $37^{\circ} \mathrm{C}$ its production is diminished [25].

From in vitro analysis, authors of previous studies suggested that the gene products of the genes $g p H$ [phage L-413C] and $g p 17$ [phage $\Phi A 1122$ ] likely represent the tail fibers RBP of these phages [15,16]. Typically for tail fibers, the N-terminus of the RBP connects the RBP with the rest of the phage, whereas the C-terminus, which is oriented away from the phage, forms the binding domain for the host receptor [22-24]. Nobrega et al. (2018) described that, due to the length and complexity of tail fiber proteins, chaperones are often required for their proper folding and functionality [20]. Garcia et al. (2008) proposed that the gene product of $g p G$ located downstream of the sequence of the gene of proposed tail fiber protein $\mathrm{GpH}$ in the genome of phage L-413C encodes a protein $(\mathrm{GpG})$ that serves the assembly of the tail fiber protein [15]. This notion is supported by data from the closely related P2 phage. Here, gene product $\mathrm{G}$ possesses a function in the assembly of the gene product $\mathrm{H}$ which is the tail fiber protein in P2 phage [29]. Coexpression of the gpH RBP gene (of phage L-413C) with the downstream $g p G$ gene, however, did in our hands not improve RBP yield or solubility (unpublished results).

The present work revealed different host specificities of the RBP from phages L-413C and $\Phi A 1122$, respectively. Garcia et al. (2008) suggested the mosaic genetic origin of the L-413C-RBP (GpH) protein being responsible for its ability to distinguish between $Y$. pestis and Y. pseudotuberculosis cells [15]. The authors postulated a hybrid protein pattern composed of four different regions for this RBP. Two sections of the $\mathrm{GpH}$ protein, the N-terminal $207-(\geq 91 \%$ match) and C-terminal 137 amino acids (59\% match), have a significant similarity with the RBP of phage P2 protein $\mathrm{H}$ [15]. The remaining middle part of the phage L-413C-RBP is not homologous to that of protein $\mathrm{H}$ from P2 but rather seems to be a mosaic itself with highest partial similarities to other enterobacterial phage tail fiber proteins. The 
authors proposed this $\mathrm{GpH}$ (the RBP) to be a hybrid resulting from recombination events. The same authors also proposed that the specific substitutions in the polypeptide were responsible for changes in the host recognition region that sculptured the particularly high specificity of the L-413C phage towards Y. pestis [15]. In contrast, the RBP gene of phage $\Phi A 1122$ shows an overall nucleotide sequence identity of $85.3 \%$ with the phage T7-RBP gene 17 ( $g p 17$ ) [30], whereby the first 500 nucleotides at the $5^{\prime}$-end are $93.6 \%$ identical, while the 500 nucleotides at the 3 '-end are only $73.4 \%$ identical [16]. Similar to the RBP gene of phage L-413C, the authors concluded that an evolutionary recombination event led to a change in the phage $\Phi A 1122$ host spectrum [15]. Though the RBPs characterized in this work originate from unrelated phages, genetic rearrangements, mutations and likely horizontal gene transfer thus have achieved, each from a unique phage progenitor chassis, very high host specificities.

The capsule-like fraction 1 (F1) antigen produced by $Y$. pestis is a specific marker for pathogen identification. It is thus not surprising that the $\mathrm{F} 1$ antigen is the basis of a variety of detection methods [31]. F1 antigen biosynthesis is unique to Y. pestis and upregulated at $37^{\circ} \mathrm{C}$ (mammalian phase of the infection cycle) $[5,6]$. It is believed that the induction of expression at $37^{\circ} \mathrm{C}$ is related to the capsule's role in protecting the bacterium from being attacked and killed by phagocytic host cells [6]. At temperatures below $37^{\circ} \mathrm{C}$, the expression level of the $\mathrm{F} 1$ antigen gene is significantly reduced, limiting F1 tests on cells grown under such conditions [32]. Initially, we had expected that RBP-dependent detection of $Y$. pestis as described in this work would be negatively impeded by the presence of $\mathrm{F} 1$ antigen at $37^{\circ} \mathrm{C}$. Because the $\mathrm{F} 1$ antigen is anchored to the outer membrane [6], it can be assumed that capsule subunits on the cell surface would cover layers of the LPS core close to the cell surface but not the terminal layers located further out. Agreeing to this notion, RBP binding became noticeably less efficient (decrease of RBP-reporter signal) for the RBP of $\Phi$ A1122 phage when capsule formation increased at $37^{\circ} \mathrm{C}$. A likely cause for this could be a shielding effect of the growing $\mathrm{F} 1$ antigen capsule against the $\Phi A 1122$ phage surface receptor Kdo/Ko in the core of the LPS of Y. pestis [18,19]. The Kdo/Ko surface receptors are directly connected to lipid A and are therefore significantly closer to the cell surface than the terminal N-acetylglucosamine, which serves as the likely surface receptor for the RBP of phage L-413C [19]. This may explain why the RBP-reporter of phage L-413C was still able to bind to its cognate, more peripherally positioned, primary surfaces receptor but the RBP of the phage $\Phi$ A1122 was not.

Strains from the Y. pseudotuberculosis complex, comprising Y. pseudotuberculosis, Y. pestis, Y. similis and $Y$. wautersii, form a clade of closely related species based on $16 \mathrm{~S}$ rRNA gene sequences [7] making it necessary to test RBP-reporter specificity on members of this clade. Other relatives of $Y$. pestis tested were strains of the enteropathogenic species $Y$. enterocolitica, which is divided into the subspecies enterocolitica and palearctica [33]. At a growth temperature of $28^{\circ} \mathrm{C}$, the RBP of both phages L-413C and $\Phi$ A1122 showed high specificities for $Y$. pestis clearly discriminating against other species of the Y. pseudotuberculosis complex (incl. Y. pseudotuberculosis) and Y. enterocolitica. Even at $37^{\circ} \mathrm{C}$ the RBP tested negative for binding to $Y$. similis, $Y$. wautersii and $Y$. enterocolitica. While no binding of the RBP of phage L-413C to Y. pseudotuberculosis occurred when cultures were grown at $37^{\circ} \mathrm{C}$, the RBP of phage ФA1122 did, albeit weaker than to Y. pestis (Figures 5 and 6). This can be expected, for the receptor of phage $\Phi A 1122$ is the Kdo/Ko region of the LPS nuclear structure, which occurs in the LPS of both Y. pestis and Y. pseudotuberculosis but not in the LPS of e.g., Y. enterocolitica [34]. Skurnik et al. (2012) demonstrated that phage $\Phi$ A1122 does not infect $Y$. enterocolitica strains agreeing with the lack of RBP binding in our specificity tests [34]. This difference in binding to $Y$. pseudotuberculosis cells at $37^{\circ} \mathrm{C}$ of phage L-413C- and $\Phi$ A1122-RBP also fits to earlier observations when the parental complete phages were used to infect cells in plaque assays. Phage $\Phi$ A1122 infected Y. pseudotuberculosis at $37^{\circ} \mathrm{C}$ as demonstrated by different studies using a large number of tested strains [16,35]. This earlier work also indicated that in practice differentiation between $Y$. pestis and $Y$. pseudotuberculosis by susceptibility to phage $\Phi A 1122$ is robust up to $28^{\circ} \mathrm{C}$ [16]. The temperature-regulated biosynthesis of the O-PS chains leads to the formation of long O-PS chains below $30^{\circ} \mathrm{C}$, whereas short chains or no O-PS formation occurs at temperatures above $37^{\circ} \mathrm{C}$ [34]. Thus, as production of $Y$. pseudotuberculosis O-PS is strongly 
diminished at temperatures above $30{ }^{\circ} \mathrm{C}$, attachment of phage $\Phi$ A1122 becomes possible. Therefore, Filippov et al. (2011) proposed that the O-antigen blocks the phage receptor in the inner core of Y. pseudotuberculosis LPS at lower temperatures [19].

Conversely, in the present work binding of L-413C-RBP was exclusive to Y. pestis cells. We tested four $Y$. pseudotuberculosis strains and found them to be negative for binding. Tests with more than 1200 strains of $Y$. pseudotuberculosis and 7000 strains of $Y$. pestis (isolated from various plaque foci around the world) also confirmed that phage L-413C has a uniquely high specificity for Y. pestis [36]. According to that publication, there are only 10 atypical Y. pestis strains resistant to phage L-413C. None of these strains were available for the present work.

In an earlier study, specificities of phages against $Y$. pestis were evaluated. For instance, phages of so-called serovar 1 usually exhibit only partial specificity and lyse between 74 and $100 \%$ of the tested Y. pestis strains, a significant fraction of Y. pseudotuberculosis (25-65\%), Y. enterocolitica (up to 15\%) and other enterobacterial isolates [16]. Phage $\Phi A 1122$ scores top specificity values within this group [35]. The phage was capable of infecting some $Y$. pseudotuberculosis strains at $37^{\circ} \mathrm{C}$ but after cultivation at $20^{\circ} \mathrm{C}$ exclusively lysed $Y$. pestis. These observations were confirmed by further testing; yet two $Y$. pestis strains among the thousands deposited in the culture collection of the Center for Disease Control and Prevention (CDC) proved to be resistant to this phage [16]. The authors proposed that if $Y$. pestis isolates from plague outbreaks in the former Soviet Union and Mongolia, which included some atypical strains as well as some naturally phage-resistant strains, were included, the number of resistant strains would increase. Nevertheless, due to its specific and broad strain infectivity, the $\Phi$ A1122 phage has been in use by the CDC, WHO and the US Army Medical Research Institute for Infectious Diseases as a diagnostic standard (as phage lysis assay) for the confirmatory identification of $Y$. pestis $[37,38]$. Phage $\Phi A 1122$ has later been developed into a recombinant, bioluminescence-mediating reporter phage facilitating detection of $Y$. pestis at an limit of detection of $10^{2}$ cells within 60 min with little off-target signals from Y. pseudotuberculosis or Y. enterocolitica [14].

Phage L-413C belongs to a different serovar group (serovar 2) than phage $\Phi$ A1122. Typically, phages of this group can multiply in a wide range of Yersinia spp. and, with a few exceptions, such as phage L-413C, have low specificities [15]. These authors suspected that phage L-413C was highly specific for $Y$. pestis because the phage lysed all $Y$. pestis strains tested but failed to successfully infect other Yersinia spp. and the majority of other enterobacteria. So far, only a few "restriction deficient" E. coli C-strains have been identified as hosts of phage L-413C [15].

While providing specific identification and requiring little monetary investments, phage plaque assay testing is time consuming. More ideally, rapid and specific confirmatory detection techniques are needed for unambiguous pathogen identification. For $Y$. pestis, lateral flow immunochromatographic assays employing F1 capsule antibodies have been in successful use for many years and new derivatives are still being developed [10,31,39]. For instance, such invaluable rapid tests have been instrumental for on-site plague diagnostics in Madagascar since 2002 [40]. Earlier it was shown that the rapid F1 capsule test is more efficacious than bacteriological methods or the F1 ELISA as it correctly identified significantly more positive clinical samples [41]. Using a combination of bacteriological methods and F1 ELISA as reference standard, the positive predictive value of the rapid test was $90.6 \%$ and the negative predictive value $86.7 \%$ [41]. In the work at hand, with a more modest sample size, RBP-reporters derived from phages L-413C or $\Phi$ A1122 all 7 out of 7 tested $Y$. pestis strains were all positive, all 10 near neighbors were identified as negative, giving a specificity of $100 \%$ at $28{ }^{\circ} \mathrm{C}$. However, at $37^{\circ} \mathrm{C}$, due to the expected detection of Y. pseudotuberculosis strains at this temperature, these values dropped to $60 \%$ (6/10) for phage $\Phi A 1122$. Though the work described herein is a proof-of-principle study, in the future testing of larger panels of known positive and negative isolates will be required for full validation. Atypical Y. pestis strains [36] should also be included, which are currently not available to us. 


\section{Conclusions}

In conclusion, we have tested a hypothesis formulated earlier that the gene products of the genes $g p H$ (phage L-413C) and $g p 17$ (phage $\Phi A 1122$ ) are the likely RBPs of these highly specific phages of Y. pestis. By constructing fusions of phage RBPs and fluorescent proteins, we developed an assay for the rapid detection of $Y$. pestis cells which is species specific at $28^{\circ} \mathrm{C}$ for both RBP tested and remains specific at $37^{\circ} \mathrm{C}$ when the reporter included the RBP from phage L-413C. Use of the RBP from phage $\mathrm{L}-413 \mathrm{C}$ is recommended also because this RBP-reporter seems to be able to even label encapsulated cells grown at $37^{\circ} \mathrm{C}$ found after infection of mammal hosts. Such diagnostic testing is facilitated by the finding that RBP-reporter binding can also occur on formaldehyde-inactivated Y. pestis specimens.

It is therefore our expectation that such RBP-reporter assays can be applied after validation for the testing of mixed bacterial cultures (e.g., from collected fleas) and of clinical matrices, such serum or environmental samples for stationary diagnostics or field laboratories.

\section{Materials and Methods}

\subsection{Strains, Phages and Plasmids}

Strains, phages and plasmids used in this work are listed in Supplementary Table S1.

\subsection{Media, Buffer, Additives and Growth Conditions Including Growth Curves}

E. coli cultures were grown in LB broth or on LB-agar (Merck KGaA, Darmstadt, Germany) containing, if required, $20 \mu \mathrm{g} / \mathrm{mL}$ of gentamycin and $100 \mu \mathrm{g} / \mathrm{mL}$ carbenicillin (Carl Roth, Karlsruhe, Germany). Y. pestis and other Yersinia spp. were cultivated at $28^{\circ} \mathrm{C}$ (or at 6,20 or $37^{\circ} \mathrm{C}$ ) on brain-heart infusion agar plates (BHI, Merck KGaA, Darmstadt, Germany) or in $250 \mathrm{~mL}$ baffled flasks containing $50 \mathrm{~mL}$ BHI broth (TSB, Merck KGaA, Darmstadt, Germany) with shaking at $120 \mathrm{rpm}$. Y. pestis strains of risk group 3 (RG-3) were cultivated in the biosafety level 3 (BSL-3) laboratory at the Bundeswehr Institute of Microbiology (IMB). Before subjected to further testing, cells of RG-3 strains were chemically inactivated with $70 \%(\mathrm{v} / \mathrm{v})$ ethanol unless stated otherwise. Yersinia phages were propagated on $Y$. pestis EV76 cultures by standard protocols as described previously [42].

\subsection{Cloning of Phage RBP Gene Fusions}

PCR primer oligonucleotides were designed using Geneious Prime software (Biomatters Limited, Auckland, New Zealand) from DNA sequences of phage $\Phi$ A1122 (accession \#NC_004777), phage L-413C (accession \#NC_004745), mCherry-pBAD or eGFP-pBAD (Supplementary Table S2). Cloning of phage RBP genes was carried out as described previously [43]. For cloning of genes of fluorescent proteins and the putative RBP genes, the primers were designed in such a way that the recognition sites for SalI, EcoRI and BsrGI upstream and XhoI, PstI and BsiWI downstream of the fluorescence genes, which were inserted into the vector chassis pASG-IBA 105 (IBA GmbH, Göttingen, Germany), can be used for subsequent cloning of additional genes. Digesting these chassis vectors with XhoI and BsiWI and subsequent ligation of the putative RBP genes enabled cloning of RBP-reporters. In the respective expression vectors (Supplementary Table S1), the N-terminal end of the encoded recombinant protein carries a Twin-Strep tag [44] and the putative head domains of the RBP are located at the C-terminus. To this end, genes of fluorescent proteins eGFP (green) or mCherry (red) were PCR-amplified from mCherry-pBAD or $\mathrm{pEGFP-C1}$, respectively using primer pairs mCherry forward/reverse and eGFP forward/reverse (Supplementary Table S2) creating overhangs containing restriction sites for Esp3I for cloning into pASG-IBA105 expression plasmid downstream of the Twin-Strep-tag nucleotide sequence. One-step Esp3I digestion and ligation was carried out using StarGate Direct transfer cloning System (IBA GmbH, Göttingen, Germany) as described in the manufacturer's protocol and plasmids were transformed into NEB Turbo cells (New England Biolabs GmbH, Frankfurt am Main, Germany). Clones were confirmed by Sanger sequencing (Eurofins Genomics Germany GmbH, Ebersberg, Germany) of their recombinant pASG-mCherry/pASG-eGFP plasmids using primers flanking the insert. 
Genes encoding RBP were PCR-amplified from custom-synthesized GeneBlocks (ThermoFisher Scientific, Darmstadt, Germany) of E. coli codon-optimized gpH (phage L-413C, accession \#NC_004745) or gp17 (phage $\Phi A 1122$, accession \#NC_004777), respectively using primer pairs L-413Cp19-RBP F/R and A1122p42-RBP F/R (Supplementary Table S2). PCR samples were analyzed by agarose gel-electrophoresis and cut with XhoI and BsiWI (New England Biolabs GmbH, Frankfurt am Main, Germany) to generate cohesive (sticky) ends, ligated into expression vectors (Supplementary Table S1) cut with the same restriction endonucleases and transformed into chemically competent $E$. coli NEB Turbo cells (New England Biolabs GmbH, Frankfurt am Main, Germany) [42]. Individual clones were grown, inserts confirmed by colony-PCR and plasmids isolated using the QIAprep Spin Miniprep Kit (QIAGEN, Hilden, Germany). DNA sequencing of recombinant plasmids was performed by commercial services (Eurofins Genomics, Ebersberg, Germany).

\subsection{Heterologous Production of Fluorescent RBP-Reporter Fusion Proteins}

DNA of expression plasmids was transformed into chemically competent $E$. coli ArcticExpress cells. A single colony used to inoculate an overnight culture which was diluted $1 \%$ into fresh LB medium and incubated with shaking $(120 \mathrm{rpm})$ at $37^{\circ} \mathrm{C}$. After derepression of heterologous gene expression by adding anhydrotetracycline (AHT; IBA GmbH, Göttingen, Germany) at an optical density at $600 \mathrm{~nm}(\mathrm{OD} 600)$ of $0.4-0.8$ [45], incubation was continued for $24 \mathrm{~h}$ at $12{ }^{\circ} \mathrm{C}$. Successful protein biosynthesis was monitored by a change in the color of the culture medium by fluorescing E. coli cells. Cells were harvested by centrifugation $(7500 \times \mathrm{g}, 10 \mathrm{~min})$ and cell pellets stored at $-20^{\circ} \mathrm{C}$ until further use. Cell pellets were resuspended and processed as described previously [43]. Cell lysis was accomplished by mechanical means using a French Press (Emulsiflex-C3; Avestin Europe $\mathrm{GmbH}$, Mannheim, Germany). Affinity chromatography was conducted making use of the Twin-Strep-tag-Streptactin ${ }^{\circledR}$ XT system (IBA GmbH, Göttingen, Germany) including centrifugation columns (Strep-Tactin ${ }^{\circledR}$ XT Spin Columns, IBA GmbH, Göttingen, Germany), gravity-flow columns (Strep-Tactin ${ }^{\circledR} \mathrm{XT}$ sepharose, IBA GmbH, Göttingen, Germany) or Fast protein liquid chromatography (FPLC, Äkta pure, GE Healthcare Life Science, Munich, Germany) according to the manufacturer's protocols. Proteins were analyzed for correct sizes and purity by denaturing sodium dodecyl-sulfate polyacrylamide gel electrophoresis (SDS-PAGE) stained with PierceTM Reversible Protein Protein Stain (ThermoFisher Scientific, Darmstadt, Germany) and Strep-tagged protein detection after Western blotting onto nitrocellulose membranes using horseradish peroxidase-coupled StrepMAB antibodies (IBA GmbH, Göttingen, Germany) with enhanced chemiluminescence (ECL) solution (ClarityTM Western ECL Substrat Kit, Bio-Rad Laboratories, Munich, Germany) as chromogenic substrate.

\subsection{Inactivation of Y. pestis Cells}

For inactivation of $Y$. pestis cells with $70 \%$ ethanol, $1-2 \mathrm{~mL}$ of culture were centrifuged at $5000 \times g$ for $2 \mathrm{~min}$ at room temperature (RT), the pellet resuspended in $300 \mu \mathrm{L}$ phosphate-buffered saline (PBS, pH 7.2), $1200 \mu \mathrm{L}$ of $100 \%$ ethanol added and the mixture incubated for at least $15 \mathrm{~min}$ with mixing by frequently inverting the tube at RT. Cells were pelleted at $5000 \times g$ for $2 \mathrm{~min}$ at RT and the supernatant removed. Cells were washed with $1.5 \mathrm{~mL}$ of PBS and resuspended in $1 \mathrm{~mL}$ of fresh PBS. For paraformaldehyde (PFA) inactivation, $1-2 \mathrm{~mL}$ of $Y$. pestis cultures were centrifuged at $5000 \times g$ for 2 min at RT and the pellet resuspended in $1 \mathrm{~mL}$ PBS. After another wash step with PBS the cell pellet was resuspended in $250 \mu \mathrm{L}$ fresh PBS, $750 \mu \mathrm{L}$ ice-cold, $4 \%$ PFA solution was added and the mix incubated at RT for $1 \mathrm{~h}$. The sample was then centrifuged at $5000 \times g$ for $2 \mathrm{~min}$ at RT and the pellet resuspended and washed by centrifugation with PBS and finally resuspended in $1 \mathrm{~mL}$ fresh PBS. For heat inactivation, $200 \mu \mathrm{L}$ aliquots of $Y$. pestis cultures were washed in PBS by centrifugation, resuspended in $200 \mu \mathrm{L}$ of PBS and incubated for $30 \mathrm{~min}$ at $95^{\circ} \mathrm{C}$ in a heating block with temperature-controlled lid. Inactivation by peracetic acid (Terralin PAA, Schülke \& Mayr GmbH, Norderstedt, Germany) was performed by mixing $750 \mu \mathrm{L}$ aliquots of bacterial cultures with $750 \mu \mathrm{L}$ of $4 \%$ Terralin PAA followed by $15 \mathrm{~min}$ 
incubation at RT. Cells were washed twice with $1.5 \mathrm{~mL}$ of PBS and resuspended in $1 \mathrm{~mL}$ of fresh PBS. Inactivated cells were stored at $4{ }^{\circ} \mathrm{C}$ until further use.

\subsection{Labeling of Y. pestis and Other Bacterial Cells with RBP-Reporters or Antibodies}

RBP-reporter assays were carried out as described previously for B. anthracis with slight modifications [43]. Briefly, $500 \mu \mathrm{L}$ of an overnight culture of $Y$. pestis or other Yersinia spp. strains was used to inoculate $50 \mathrm{~mL}$ of fresh BHI medium in a $250 \mathrm{~mL}$ baffled shaking flask and the culture was incubated at $6,20,28$ or $37^{\circ} \mathrm{C}$ with shaking at $100 \mathrm{rpm}$. At different time points, $\mathrm{OD}_{600}$ was measured and a sample taken equivalent to $100 \mu \mathrm{L}$ of an $\mathrm{OD}_{600}$ of 1 . When cultures were grown on solid media, agar plates were used. Single colonies were picked, resuspended in $100 \mu \mathrm{L}$ PBS and diluted to a final $\mathrm{OD}_{600}$ of 1 . Samples were pelleted by centrifugation at $5000 \times \mathrm{g}$ for $5 \mathrm{~min}$ at $\mathrm{RT}$ in $1.5 \mathrm{~mL}$ centrifugation tubes, resuspended in PBS, mixed with $3 \mu \mathrm{g}$ of purified RBP-reporter protein and incubated for $10 \mathrm{~min}$ at room temperature. When testing for capsule formation $0.3 \mu \mathrm{g}$ of F1-antigen antibody (Y. pestis F1-Antigen Antibody [YPF19], GeneTex Inc., Irvine, CA, USA) was added alongside the RBP-reporter and incubation time was increased to $1 \mathrm{~h}$. After a washing step using PBS (5000 $\mathrm{g}$ for $2 \mathrm{~min}$ ), $0.3 \mu \mathrm{g}$ of goat anti-mouse Alexa Fluor ${ }^{\circledR} 647$ antibody (if RBP of phage $\Phi$ A1122 was used) or antibody Alexa Fluor $^{\circledR} 488$ (if RBP of phage L-413C was used, ThermoFisher Scientific, Darmstadt, Germany) was added, followed by incubation at room temperature for $1 \mathrm{~h}$. After a final washing step with PBS (5000 $\times g$ for $2 \mathrm{~min}$ ) $4 \mu \mathrm{L}$ were transferred into a well of a chamber slide with lid ( $\mu$-slide 8 Well, Ibidi $\mathrm{GmbH}$, Martinsried, Germany). For proper microscopic analysis of cells, suspensions were covered with a $1 \mathrm{~mm}$ thick agar-agar pad serving as a coverslip (1\% molten agar-agar solidified between two microscopy slides). Samples were analyzed for cells emitting mCherry (excitation: $587 \mathrm{~nm}$, emission: $610 \mathrm{~nm}$ ) or eGFP signal (excitation: $488 \mathrm{~nm}$, emission: $507 \mathrm{~nm}$ ) as well as for signal emanating from secondary antibodies Alexa Fluor ${ }^{\circledR} 488$ (excitation: $490 \mathrm{~nm}$, emission: $525 \mathrm{~nm}$ ) and Alexa Fluor ${ }^{\circledR}$ 647 (excitation: $650 \mathrm{~nm}$, emission: $665 \mathrm{~nm}$ ) using Axio Observer Z1 700 Confocal Laser Scanning Microscope (Carl Zeiss, Oberkochen, Germany).

Supplementary Materials: The following are available online at http://www.mdpi.com/2076-0817/9/8/611/s1, Table S1: Strains, phages and plasmids used in this work; Table S2: Oligonucleotide primers; Figure S1: Western blot of heterologously produced RBP fusion reporter proteins; Figure S2: Binding of RBP-reporters to growing cultures of $Y$. pestis EV76 cells at $28{ }^{\circ} \mathrm{C}$.

Author Contributions: Conceptualization, P.B. and G.G.; investigation and methodology, P.B. and F.B.; formal analysis, P.B. and G.G.; data curation, F.B., P.B. and G.G.; visualization, writing, F.B., P.B. H.C.S. and G.G.; supervision, validation, funding acquisition and project administration, G.G. All authors have read and agreed to the published version of the manuscript.

Funding: This research was funded by funds from the Medical Biological Defense Research Program of the Bundeswehr Joint Medical Service and partially supported by the Robert Koch-Institute through funding by the German Ministry of Health within project 1369-448.

Acknowledgments: Shanmuga Sozhamannan (Defense Biological Product Assurance Office, CBRND-EB, JPEO, Frederick, Maryland, USA) is acknowledged for the generous gift of Yersinia phages $\Phi$ A1122 and L-413C and Richard Calendar (University of Berkeley, Berkeley, California, USA for his advice on handling Yersinia phages. Thanks are due to Inga Stürz for skillful technical assistance.

Conflicts of Interest: The authors declare no conflict of interest. Opinions, interpretations, conclusions, and recommendations are those of the authors and are not necessarily endorsed by any governmental agency, department or other institutions. The funders had no role in the design of the study; in the collection, analyses, or interpretation of data; in the writing of the manuscript, or in the decision to publish the results.

\section{References}

1. Perry, R.D.; Fetherston, J.D. Yersinia pestis—Etiologic agent of plague. Clin. Microbiol. Rev. 1997, 10, 35-66. [CrossRef] [PubMed]

2. Knirel, Y.A.; Anisimov, A.P. Lipopolysaccharide of Yersinia pestis, the cause of plague: Structure, genetics, biological properties. Acta Nat. 2012, 4, 46-58. [CrossRef] 
3. Wang, C.; Stanciu, C.E.; Ehrhardt, C.J.; Yadavalli, V.K. The effect of growth temperature on the nanoscale biochemical surface properties of Yersinia pestis. Anal. Bioanal. Chem. 2016, 408, 5585-5591. [CrossRef] [PubMed]

4. Cavanaugh, D.C.; Randall, R. The role of multiplication of Pasteurella pestis in mononuclear phagocytes in the pathogenesis of flea-borne plague. J. Immunol. 1959, 83, 348-363.

5. Du, Y.; Rosqvist, R.; Forsberg, A. Role of fraction 1 antigen of Yersinia pestis in inhibition of phagocytosis. Infect. Immun. 2002, 70, 1453-1460. [CrossRef]

6. Miller, J.; Williamson, E.D.; Lakey, J.H.; Pearce, M.J.; Jones, S.M.; Titball, R.W. Macromolecular organisation of recombinant Yersinia pestis F1 antigen and the effect of structure on immunogenicity. FEMS Immunol. Med. Microbiol. 1998, 21, 213-221. [CrossRef]

7. Laukkanen-Ninios, R.; Didelot, X.; Jolley, K.A.; Morelli, G.; Sangal, V.; Kristo, P.; Brehony, C.; Imori, P.F.; Fukushima, H.; Siitonen, A.; et al. Population structure of the Yersinia pseudotuberculosis complex according to multilocus sequence typing. Environ. Microbiol. 2011, 13, 3114-3127. [CrossRef]

8. Choi, S.Y.; Rhie, G.E.; Jeon, J.H. Development of a double-antibody sandwich ELISA for sensitive detection of Yersinia pestis. Microbiol. Immunol. 2020, 64, 72-75. [CrossRef]

9. Simon, S.; Demeure, C.; Lamourette, P.; Filali, S.; Plaisance, M.; Creminon, C.; Volland, H.; Carniel, E. Fast and simple detection of Yersinia pestis applicable to field investigation of plague foci. PLOS ONE 2013, 8 , e54947. [CrossRef]

10. Tomaso, H.; Thullier, P.; Seibold, E.; Guglielmo, V.; Buckendahl, A.; Rahalison, L.; Neubauer, H.; Scholz, H.C.; Splettstoesser, W.D. Comparison of hand-held test kits, immunofluorescence microscopy, enzyme-linked immunosorbent assay, and flow cytometric analysis for rapid presumptive identification of Yersinia pestis. J. Clin. Microbiol. 2007, 45, 3404-3407. [CrossRef]

11. Tomaso, H.; Jacob, D.; Eickhoff, M.; Scholz, H.C.; Al Dahouk, S.; Kattar, M.M.; Reischl, U.; Plicka, H.; Olsen, J.S.; Nikkari, S.; et al. Preliminary validation of real-time PCR assays for the identification of Yersinia pestis. Clin. Chem. Lab. Med. 2008, 46, 1239-1244. [CrossRef] [PubMed]

12. Riehm, J.M.; Rahalison, L.; Scholz, H.C.; Thoma, B.; Pfeffer, M.; Razanakoto, L.M.; Al Dahouk, S.; Neubauer, H.; Tomaso, H. Detection of Yersinia pestis using real-time PCR in patients with suspected bubonic plague. Mol. Cell Probes 2011, 25, 8-12. [CrossRef]

13. Sergueev, K.V.; He, Y.; Borschel, R.H.; Nikolich, M.P.; Filippov, A.A. Rapid and sensitive detection of Yersinia pestis using amplification of plague diagnostic bacteriophages monitored by real-time PCR. PLoS ONE 2010, 5, e11337. [CrossRef] [PubMed]

14. Schofield, D.A.; Molineux, I.J.; Westwater, C. Diagnostic bioluminescent phage for detection of Yersinia pestis. J. Clin. Microbiol. 2009, 47, 3887-3894. [CrossRef] [PubMed]

15. Garcia, E.; Chain, P.; Elliott, J.M.; Bobrov, A.G.; Motin, V.L.; Kirillina, O.; Lao, V.; Calendar, R.; Filippov, A.A. Molecular characterization of L-413C, a P2-related plague diagnostic bacteriophage. Virology 2008, 372, 85-96. [CrossRef]

16. Garcia, E.; Elliott, J.M.; Ramanculov, E.; Chain, P.S.; Chu, M.C.; Molineux, I.J. The genome sequence of Yersinia pestis bacteriophage phiA1122 reveals an intimate history with the coliphage T3 and T7 genomes. J. Bacteriol. 2003, 185, 5248-5262. [CrossRef]

17. Hendrix, R.W.; Smith, M.C.; Burns, R.N.; Ford, M.E.; Hatfull, G.F. Evolutionary relationships among diverse bacteriophages and prophages: All the world's a phage. Proc. Natl. Acad. Sci. USA 1999, 96, 2192-2197. [CrossRef]

18. Kiljunen, S.; Datta, N.; Dentovskaya, S.V.; Anisimov, A.P.; Knirel, Y.A.; Bengoechea, J.A.; Holst, O.; Skurnik, M. Identification of the lipopolysaccharide core of Yersinia pestis and Yersinia pseudotuberculosis as the receptor for bacteriophage phiA1122. J. Bacteriol. 2011, 193, 4963-4972. [CrossRef]

19. Filippov, A.A.; Sergueev, K.V.; He, Y.; Huang, X.Z.; Gnade, B.T.; Mueller, A.J.; Fernandez-Prada, C.M.; Nikolich, M.P. Bacteriophage-resistant mutants in Yersinia pestis: Identification of phage receptors and attenuation for mice. PLOS ONE 2011, 6, e25486. [CrossRef]

20. Nobrega, F.L.; Vlot, M.; de Jonge, P.A.; Dreesens, L.L.; Beaumont, H.J.E.; Lavigne, R.; Dutilh, B.E.; Brouns, S.J.J. Targeting mechanisms of tailed bacteriophages. Nat. Rev. Microbiol. 2018, 16, 760-773. [CrossRef]

21. Larina, V.S.; Anisimov, P.I.; Adamov, A.K. A novel strain of plague bacteriophage for identification of Pasteurella pestis. Probl. Part. Danger. Infect. 1970, 11, 132-136. 
22. Letarov, A.V.; Kulikov, E.E. Adsorption of bacteriophages on bacterial cells. Biochemistry (Mosc) 2017, 82, 1632-1658. [CrossRef] [PubMed]

23. Simpson, D.J.; Sacher, J.C.; Szymanski, C.M. Development of an assay for the Identification of receptor binding proteins from bacteriophages. Viruses 2016, 8, 17. [CrossRef] [PubMed]

24. Singh, A.; Arutyunov, D.; Szymanski, C.M.; Evoy, S. Bacteriophage based probes for pathogen detection. Analyst 2012, 137, 3405-3421. [CrossRef] [PubMed]

25. Raetz, C.R.; Whitfield, C. Lipopolysaccharide endotoxins. Annu. Rev. Biochem. 2002, 71, 635-700. [CrossRef]

26. Knirel, Y.A.; Lindner, B.; Vinogradov, E.V.; Kocharova, N.A.; Senchenkova, S.N.; Shaikhutdinova, R.Z.; Dentovskaya, S.V.; Fursova, N.K.; Bakhteeva, I.V.; Titareva, G.M.; et al. Temperature-dependent variations and intraspecies diversity of the structure of the lipopolysaccharide of Yersinia pestis. Biochemistry 2005, 44, 1731-1743. [CrossRef]

27. Prior, J.L.; Parkhill, J.; Hitchen, P.G.; Mungall, K.L.; Stevens, K.; Morris, H.R.; Reason, A.J.; Oyston, P.C.; Dell, A.; Wren, B.W.; et al. The failure of different strains of Yersinia pestis to produce lipopolysaccharide $\mathrm{O}$-antigen under different growth conditions is due to mutations in the O-antigen gene cluster. FEMS Microbiol. Lett. 2001, 197, 229-233. [CrossRef]

28. Frirdich, E.; Whitfield, C. Lipopolysaccharide inner core oligosaccharide structure and outer membrane stability in human pathogens belonging to the Enterobacteriaceae. J. Endotoxin. Res. 2005, 11, 133-144.

29. Haggård-Ljungquist, E.; Halling, C.; Calendar, R. DNA sequences of the tail fiber genes of bacteriophage P2: Evidence for horizontal transfer of tail fiber genes among unrelated bacteriophages. J. Bacteriol. 1992, 174, 1462-1477. [CrossRef]

30. Steven, A.C.; Trus, B.L.; Maizel, J.V.; Unser, M.; Parry, D.A.; Wall, J.S.; Hainfeld, J.F.; Studier, F.W. Molecular substructure of a viral receptor-recognition protein. The gp17 tail-fiber of bacteriophage T7. J. Mol. Biol. 1988, 200, 351-365. [CrossRef]

31. Hsu, H.L.; Chuang, C.C.; Liang, C.C.; Chiao, D.J.; Wu, H.L.; Wu, Y.P.; Lin, F.P.; Shyu, R.H. Rapid and sensitive detection of Yersinia pestis by lateral-flow assay in simulated clinical samples. BMC Infect. Dis. 2018, 18, 402. [CrossRef]

32. Prior, J.L.; Titball, R.W. Monoclonal antibodies against Yersinia pestis lipopolysaccharide detect bacteria cultured at 28 degrees C or 37 degrees C. Mol. Cell Probes 2002, 16, 251-256. [CrossRef]

33. Neubauer, H.; Aleksic, S.; Hensel, A.; Finke, E.J.; Meyer, H. Yersinia enterocolitica 16S rRNA gene types belong to the same genospecies but form three homology groups. Int. J. Med. Microbiol. 2000, 290, 61-64. [CrossRef]

34. Skurnik, M. Yersinia surface structures and bacteriophages. Adv. Exp. Med. Biol. 2012, 954, $293-301$. [PubMed]

35. Gunnison, J.B.; Larson, A.; Lazarus, A.S. Rapid differentiation between Pasteurella pestis and Pasteurella pseudotuberculosis by action of bacteriophage. J. Infect. Dis. 1951, 88, 254-255. [CrossRef] [PubMed]

36. Imamaliev, O.G.; Serebryakova, V.G.; Anisimova, T.I.; Plotnikov, O.P.; Sergeeva, G.M.; Goldfarb, L.M.; Larina, V.S. Comparative Estimation of Activity and Specificity of Diagnostic Plague Bacteriophages, L-413C, and the Pokrovskaya Phage; Bektemirov, T.A.Z.Y., Litvinova, M.Y., Eds.; Mechnikov Insitute Press: Moscow, Russia, 1986.

37. Centers for Disease Control and Prevention; National Centre for Infectious Diseases; Division of Vector-Borne Diseases; World Health Organization; Division E; Communicable Disease. Laboratory Manual of Plague Diagnostic Tests; Centers for Disease Control and Prevention: Atlanta, GA, USA; World Health Organization: Geneva, Switzerland, 2000.

38. Dennis, D.T.; Gage, K.L.; Gratz, N.; Poland, J.D.; Tikhomirov, E. Plague Manual: Epidemiology, Distribution, Surveillance, and Control; World Health Organization: Geneva, Switzerland, 1999.

39. Prentice, K.W.; DePalma, L.; Ramage, J.G.; Sarwar, J.; Parameswaran, N.; Petersen, J.; Yockey, B.; Young, J.; Joshi, M.; Thirunavvukarasu, N.; et al. Comprehensive laboratory evaluation of a lateral flow assay for the detection of Yersinia pestis. Health Secur. 2019, 17, 439-453. [CrossRef] [PubMed]

40. Baril, L.; Valles, X.; Stenseth, N.C.; Rajerison, M.; Ratsitorahina, M.; Pizarro-Cerda, J.; Demeure, C.; Belmain, S.; Scholz, H.; Girod, R.; et al. Can we make human plague history? A call to action. BMJ Glob. Health 2019, 4, e001984. [CrossRef]

41. Chanteau, S.; Rahalison, L.; Ralafiarisoa, L.; Foulon, J.; Ratsitorahina, M.; Ratsifasoamanana, L.; Carniel, E.; Nato, F. Development and testing of a rapid diagnostic test for bubonic and pneumonic plague. Lancet 2003, 361, 211-216. [CrossRef] 
42. Sambrook, J. Molecular Cloning: A Laboratory Manual, 3rd ed.; Cold Spring Harbor Laboratory Press: New York, NY, USA, 2001.

43. Braun, P.; Wolfschläger, I.; Reetz, L.; Bachstein, L.; Jacinto, A.C.; Tocantins, C.; Poppe, J.; Grass, G. Rapid microscopic detection of Bacillus anthracis by fluorescent receptor binding proteins of bacteriophages. Microorganisms 2020, 8, 934. [CrossRef]

44. Schmidt, T.G.; Batz, L.; Bonet, L.; Carl,U.; Holzapfel, G.; Kiem, K.; Matulewicz, K.; Niermeier, D.; Schuchardt, I.; Stanar, K. Development of the Twin-Strep-tag $(\mathrm{R})$ and its application for purification of recombinant proteins from cell culture supernatants. Protein Expr. Purif. 2013, 92, 54-61. [CrossRef]

45. Grass, G.; Rensing, C. CueO Is a multi-copper oxidase that confers copper tolerance in Escherichia coli. Biochem. Biophys. Res. Commun. 2001, 286, 902-908. [CrossRef] [PubMed]

(C) 2020 by the authors. Licensee MDPI, Basel, Switzerland. This article is an open access article distributed under the terms and conditions of the Creative Commons Attribution (CC BY) license (http://creativecommons.org/licenses/by/4.0/). 